\title{
A Sociedade Brasileira de Medicina Tropical e a ética em pesquisa envolvendo seres humanos no Brasil
}

\author{
The Brazilian Society of Tropical Medicine and ethics \\ in human research in Brazil
}

Bruno Rodolfo Schlemper Junior ${ }^{1}$

\begin{abstract}
RESUMO
0 autor faz o resgate histórico do Código dos Direitos das Comunidades, documento ético, pioneiro no Brasil, aprovado, em 1986, pela Sociedade Brasileira de Medicina Tropical e que trata da proteção das comunidades e do respeito aos direitos humanos nas pesquisas envolvendo populações humanas, especialmente aquelas vulneráveis, social e culturalmente.
\end{abstract}

Palavras-chaves: Sociedade Brasileira de Medicina Tropical. Código dos Direitos das Comunidades. História da Ética em Pesquisa em Seres Humanos. Comunidade vulnerável. Direitos humanos.

\begin{abstract}
The author retrieves the history of the Code of Community Rights, a pioneering ethical document within Brazil that was approved in 1986 by the Brazilian Society of Tropical Medicine and which deals with protection for communities and human rights in research involving human populations, especially those that are socially and culturally vulnerable.
\end{abstract}

Key-words: Brazilian Society of Tropical Medicine. Code of Community Rights. History of Ethics in Human Research. Vulnerable Community. Human rights.

A primeira legislação brasileira sobre ética em pesquisa envolvendo seres humanos foi a Resolução No $01 / 1988^{1}$, editada pelo Conselho Nacional de Saúde (CNS), a qual foi substituída pelas atuais normas, a Resolução nº CNS 196/96² e suas resoluções complementares. Esta legislação criou e normatizou 0 atual sistema de controle ético em pesquisas envolvendo seres humanos, tendo como fundamento os principais documentos éticos internacionais, a Constituição da República Federativa do Brasil de 1988 e a legislação nacional correlata. A partir de então, o Brasil passou a figurar com destaque entre os países que possuem uma legislação ética adequada.

Raros artigos que registram a construção deste importante acervo ético no Brasil referem a participação da Sociedade Brasileira de Medicina Tropical, a qual foi ressaltada por Goldim ${ }^{4}$. Desta forma, resgata-se, agora, por uma questão de justiça histórica, o importante papel desempenhado pela Sociedade Brasileira de Medicina Tropical ao longo de seus 46 anos de

\footnotetext{
1. Curso Medicina Universidade do Oeste de Santa Catarina, Joaçaba, SC, Comissão Nacional de Ética em Pesquisa (CONEP), Comitê de Ética em Pesquisa da Secretaria de Estado da Saúde de Santa Catarina (CEP/SES/SC).

Endereço para correspondência: Prof. Bruno Rodolfo Schlemper Junior. Av. Júlio Dácia Barreto 387, Saco dos Limões, 88040-520 Florianópolis, SC.

Tel: 5548 3233-2064; 5548 9972-2181

e-mail: brunojr@terra.com.br

Recebido para publicação em 16/4/08

Aceito em 03/04/2009
}

existência, por ter elaborado e aprovado o primeiro documento sobre recomendações éticas em pesquisa em comunidades no Brasil. Assim, em 1986, durante o XXII Congresso da Sociedade Brasileira de Medicina Tropical (Belo Horizonte) foi aprovado, na Assembléia Geral dos Sócios, o denominado Código dos Direitos da Comunidade ${ }^{6}$ o qual, na verdade, representou o primeiro documento ético brasileiro a incorporar as recomendações e orientações do Código de Nuremberg (1947), da Declaração de Helsinque II (1983) e do Conselho de Organizações Internacionais de Ciências Médicas/OMS (CIOMS) (1982) e a apresentar, pela primeira vez, propostas concretas de proteção das comunidades trabalhadas. Este Código, inédito em nosso país, adotou como premissa: Os países em desenvolvimento são, freqüentemente, campos privilegiados para experiências que envolvem populações. Estes países abrigam também contingentes populacionais importantes que não têm garantidos seus direitos mínimos de cidadania. Nestas circunstâncias, na pesquisa científica que envolve, direta ou indiretamente, populações humanas, é fundamental que se tomem cuidados especiais para que sejam respeitados, em sua plenitude, os direitos humanos das populações envolvidas. A necessidade de cuidados especiais é tanto maior quanto mais desinformada estiver a população em relação aos conhecimentos científicos que fazem parte do equipamento do pesquisador e, portanto, menos capaz de se defender de procedimentos potencialmente nocivos ao seu bem-estar coletivo e/ou individual. 
Na mesma Assembléia Geral, foram aprovadas as seguintes diretrizes éticas deste Código dos Direitos da Comunidade:

1). A comunidade tem o direito de ser informada sobre a natureza, os objetivos, as vantagens e os eventuais riscos da pesquisa à qual vai ser submetida;

2). Ninguém pode ser submetido a um processo experimental sobre o qual não tenha sido previamente informado e sem a sua expressa anuência;

3). Nenhum processo experimental pode ser construído de forma a sonegar à comunidade envolvida medidas preventivas e/ou terapêuticas, no todo ou em parte;

4). Nenhuma comunidade pode ser submetida a experiência(s) que possa $(m)$ implicar agravar os riscos de saúde aos quais está habitualmente submetida;

5). A recusa pela comunidade em se submeter a um dado processo experimental não implicará privação das ações de saúde às quais esteja habilitada.

Também, na mesma oportunidade, foram aprovadas duas sugestões de encaminhamento dos Direitos das Comunidades, como seguem:

1). incorporá-los ao Código de Ética Médica, pois assim este código, além de examinar, julgar e se necessário punir a prática médica na sua relação com o doente individualmente, poderá também legislar quanto às práticas que se estendem às populações;

2). que sejam criados nos órgãos financiadores de pesquisas (CNPq, FINEP, FAPESP, etc.) comissões de ética para examinar os projetos submetidos, sob a ótica do respeito, aos direitos humanos das populações.

Ainda, em 1986, foi aprovado pela Sociedade Brasileira de Medicina Tropical e pela Sociedade Brasileira de Antropologia, o Code OfCommunity Health Rights ${ }^{3}$. 0 texto possui, basicamente, as mesmas premissas, diretrizes e sugestões já mencionadas, apenas com algumas ampliações quanto aos cuidados éticos e com a sugestão de criação de Comitês de Ética em Pesquisa em hospitais, escolas médicas e centros de pesquisa, exatamente como determinado pela atual normativa ética, dez anos após, em 1996. Este mesmo Código foi, ainda, utilizado para a elaboração das Diretrizes Internacionais para as Pesquisas Biomédicas (CIOMS/1993) ${ }^{4}$ e, em 1994, também como fonte para as diretrizes éticas propostas à Fundação de Apoio à Pesquisa do Estado de São Paulo5.

Percebe-se, portanto, que as preocupações da Sociedade Brasileira de Medicina Tropical, em que pese seu campo de ação restrito aos tropicalistas brasileiros, precederam em dez anos as orientações éticas atuais, ao proporem aos seus associados, que estas pesquisas realizadas em países em desenvolvimento, deveriam ter o consentimento prévio dos indivíduos, a proteção dos carentes e das pessoas vulneráveis, social e culturalmente, assim como o retorno dos benefícios às comunidades, exigências éticas incluídas na atual normativa.

\section{REFERÊNCIAS}

1. Conselho Nacional de Saúde. Resolução 01/1988. Diário Oficial da União, Brasília, 14 junho, p.10713-10718, 1988.

2. Conselho Nacional de Saúde. Resolução 196/96 - Diretrizes e Normas Regulamentadoras de Pesquisas Envolvendo Seres Humanos. Diário Oficial da União, Brasília, 16 outubro, p. 21.082-21.085, 1996.

3. Comunicações. Code of Community Health Rights. Revista do Instituto de Medicina Tropical de São Paulo 28: 278, 1986.

4. Goldim, JR. Bioética e pesquisa no Brasil. In: Kipper DJ (org) Ética, teoria e prática. Uma visão multidisciplinar. Editora da Pontifícia Universidade Católica do Rio Grande do Sul, p. 17-28, 2006.

5. Group on Bioethics and Population Research. Ethical guidelines for FAPESPsponsored research on human populations. Revista do Instituto de Medicina Tropical de São Paulo 36: 555-556, 1994.

6. Sociedade Brasileira de Medicina Tropical. Noticiário. Assembléia Geral dos Sócios. Revista da Sociedade Brasileira de Medicina Tropical 19: 61-62, 1986. 